\title{
Influence of the Replacement of Ungraded-PKS Aggregate on Properties of Lightweight Pervious Concrete
}

\author{
M. F. M. Jaafar ${ }^{1,}$, N. Ghazali1, K. Muthusamy ${ }^{1}$, E. S. A. Wahab ${ }^{1}$ and A. Ismail1 \\ ${ }^{1}$ Faculty of Civil Engineering Technology, Universiti Malaysia Pahang, 26300 Gambang, Pahang, Malaysia.
}

\begin{abstract}
Pervious concrete is not environmentally friendly due to the presence of nonrenewable material in its production. Pervious concrete has made a comeback as a green infrastructure and researchers came up with a proposal to use waste materials that potentially to work well as material in pervious concrete. The used of palm kernel shell (PKS) in pervious concrete is consider brilliant because Malaysia is of the larger oil palm producer in the world. In this study, the natural aggregate was partially replaced by $0,10,15$, and $20 \%$ by weight of PKS aggregate to produce lightweight pervious concrete based PKS. The testing conducted comprise of density, void content, compressive strength, and flexural strength. The inclusion of PKS aggregate reduces the mechanical properties of pervious concrete but is significantly higher than recommended in the standard, utilizing some PKS aggregate as partial aggregate at up to $20 \%$ substitution level can produce lightweight PKS-pervious concrete. The pervious concrete containing $10 \%$ of PKS aggregate presented the most optimum mixture. Besides, the use of PKS as aggregate replacement in pervious concrete mixture indicates a good potential towards sourcing alternative sustainable materials for concrete.
\end{abstract}

\section{ARTICLE HISTORY}

Received: SEP 22, 2021

Revised: OCT 26, 2021

Accepted: NOV 2, 2021

\section{KEYWORDS}

Pervious concrete

Palm kernel shell

aggregate

Void content

Sustainable materials

\section{INTRODUCTION}

In Malaysia, pervious concrete was known but not practically used by a local contractor. Even though the benefits of using pervious concrete had been discovered, the applications of pervious concrete in construction still not been applied. Pervious concrete is composed of coarse aggregate coated with a cement paste as a binder and contains little or no fine aggregate [1]. Because of the absence of fine aggregate, generally, density of pervious concrete is ranged between 1600 to $2000 \mathrm{~kg} / \mathrm{m}^{3}$, and 15 to $30 \%$ of its volume consists of interconnected void with a compressive strength of 2.8 to $28 \mathrm{MPa}$ $[2,3]$. However, Mehta et al. [4] identified that conventional pervious concrete commonly has compressive strength from 3 to $10 \mathrm{MPa}$. The high porosity in pervious concrete reduces its strength properties compared to ordinary concrete [5]. Thus, the production of pervious concrete is considerably different to others concrete. There are no generic methods were proposed for pervious concrete mix proportioning. Traditionally, pervious concrete was used in parking areas, light-traffic areas, pedestrian walkways, and greenhouses, thus contributes to sustainable construction [6, 7].

In formulating pervious concrete, aggregate gradation is crucial thus selection of aggregates size need to be focused in order to obtain concrete properties required by the specification. The concrete industry has been estimated to consume about nine billion tonnes of natural aggregates per year. Thus, the intervention into looking for alternative sources were emphasized. The idea of replacing construction material with waste materials as aggregate replacement leads a rapid development in the field of concrete technology. No doubt, there are numerous researches have been reviewed on the use of waste materials as aggregate replacement in producing pervious concrete $[8,9]$. The utilization of waste materials is because of their properties, and it can support the effectiveness of waste management to landfill. Demands for construction materials have risen to serve the rapidly growing global population. AlShareedah and Nassiri [9] reported that the potential to replace the ingredients in pervious concrete had become the main intention for the present study. One of the current global developments is based on recycling waste materials and waste by-products as an alternative ingredient in the concrete mixture [10]. However, the benefits and limitations of using various agro-forestry wastes (biomass) in pervious concrete concerning the mechanical properties have little been explored and reported. Realization on the importance of reducing waste disposed to the surrounding, has resulted in the development of a sustainable lightweight pervious concrete by replacing natural coarse aggregate.

The application of these wastes as an aggregate replacement in civil engineering provides a wide selection of alternative material, thus reducing their disposal, but existing studies on lightweight pervious concrete are very limited [11]. Thus, the selection of PKS as raw material in lightweight pervious concrete and their effect on its properties need to be studied extensively. Additionally, the previous studies have used PKS as a partial replacement restricted either in concrete, asphalt, and pavement [12]. Evidently, pervious concrete containing oil palm kernel shell and cockle shell as an aggregate replacement (from 25 to $75 \%$ by mass) can achieve compressive strength ranging from between 6 to $14 \mathrm{MPa}$ $[13,14,15]$. Previous researchers also found that regenerative waste material could make pervious concrete with a compressive strength ranging from 9 to $13 \mathrm{MPa}$ and porosity of 30 to $50 \%$ of volume at 28 days $[11,16]$. Another study 
has also confirmed that the pervious concrete produced with over burnt brick aggregate gives the value of compressive strength in the range of 3 to $10 \mathrm{MPa}$ [8]. According to Sharif et al. [17] observed that the replacement of aggregate with $20 \%$ engineered biomass aggregate (EBA) can reach the compressive strength at $8.1 \mathrm{MPa}$. Therefore, it is concluded that the compressive strength of lightweight pervious concrete is remarkable in ranges of $6 \mathrm{MPa}$ and the possibility attaining $14 \mathrm{MPa}$ depends on selective materials and production. Typically, the flexural strength of conventional pervious concrete ranging from 1 to $3.8 \mathrm{MPa}[18,19,20]$.

In this present study, the utilization of agro-forestry waste, namely palm kernel shell (PKS) aggregate is conducted in the pervious concrete mixture. In addition, Malaysia is an ideal country to respond to sustainability in the construction industry by being one of the largest oil palm producers. In Malaysia, the palm oil industry accounts for approximately $85.5 \%$ if the total biomass produced [21]. Khankhaje et al. [13] was also found that the side effect of becoming the largest oil palm producer was the quantity of oil palm waste dumped was millions of tonnes annually. The construction industry promotes sustainability in production issues with the use of solid waste material as coarse aggregate. This will be the primary motivation to pursue the present study. It is hypothesized that PKS partially replaced as aggregate, thus contributing to the enhancement of properties and it is potentially becoming the sustainable material for pervious concrete.

\section{EXPERIMENTAL PROGRAM}

\section{Materials}

Four (4) main materials were used to produce pervious concrete and pervious concrete containing different content of PKS aggregate. The materials used are ordinary Portland cement, aggregate, PKS and water. The cementitious used is ordinary Portland cement Type I complying with MS: Part I: 2007 provided by a local supplier. The crushed gravel was used as an aggregate and it was fixed to $10 \mathrm{~mm}$. The properties of natural aggregate used have a specific gravity of 2.82 and water absorption of $1.61 \%$. The raw PKS was collected from a local palm oil mill, Kilang Sawit Panching, Kuantan. The PKS aggregate used are classified as 'young prime' from 10 to 15 years of age. In this study, ungraded-PKS aggregate was used as a partial replacement for the conventional aggregate. The raw PKS were pre-treated by soaking the PKS with $5 \% \mathrm{NaOH}$ solution for 4 hours to remove the oil coating and dust. Then, the PKS aggregate was washed using tap water to remove the excess of $\mathrm{NaOH}$. After washed, the PKS aggregates were dried and kept at room temperature. Due to the use of ungraded-PKS sizes, a sieve analysis test was performed to assess the particle size distribution of the PKS aggregates in accordance with BS EN933-2. Figure 1 depicts the particle size distribution of PKS aggregates determined by using sieve analysis. Approximately $60 \%$ from the total weight of PKS the particle sizes are passing through $5 \mathrm{~mm}$ and retained on the $10 \mathrm{~mm}$ sieved. It can be verified that PKS used were achieved the requirement as aggregate. In this study, the PKS aggregate differ in size from 4.5, 9.5 and $10.5 \mathrm{~mm}$. The appearance of natural aggregate and PKS aggregate are shown in Figure 2. The specific gravity, density, and water absorption of the PKS aggregate were also carried out to determine the properties with compliance to BS 812-2. The results indicated that the specific gravity, water absorption and density of PKS aggregate obtained were $1.26,25.64 \%$ and $1259 \mathrm{~kg} / \mathrm{m}^{3}$, respectively. Previous researchers have also reported the specific gravity of PKS ranging between 1.17 to 2.29, and water absorption from 14 to $33 \%$ [21]. It was also found that the density of PKS aggregate used in this study was about 53\% lower than the natural aggregate.

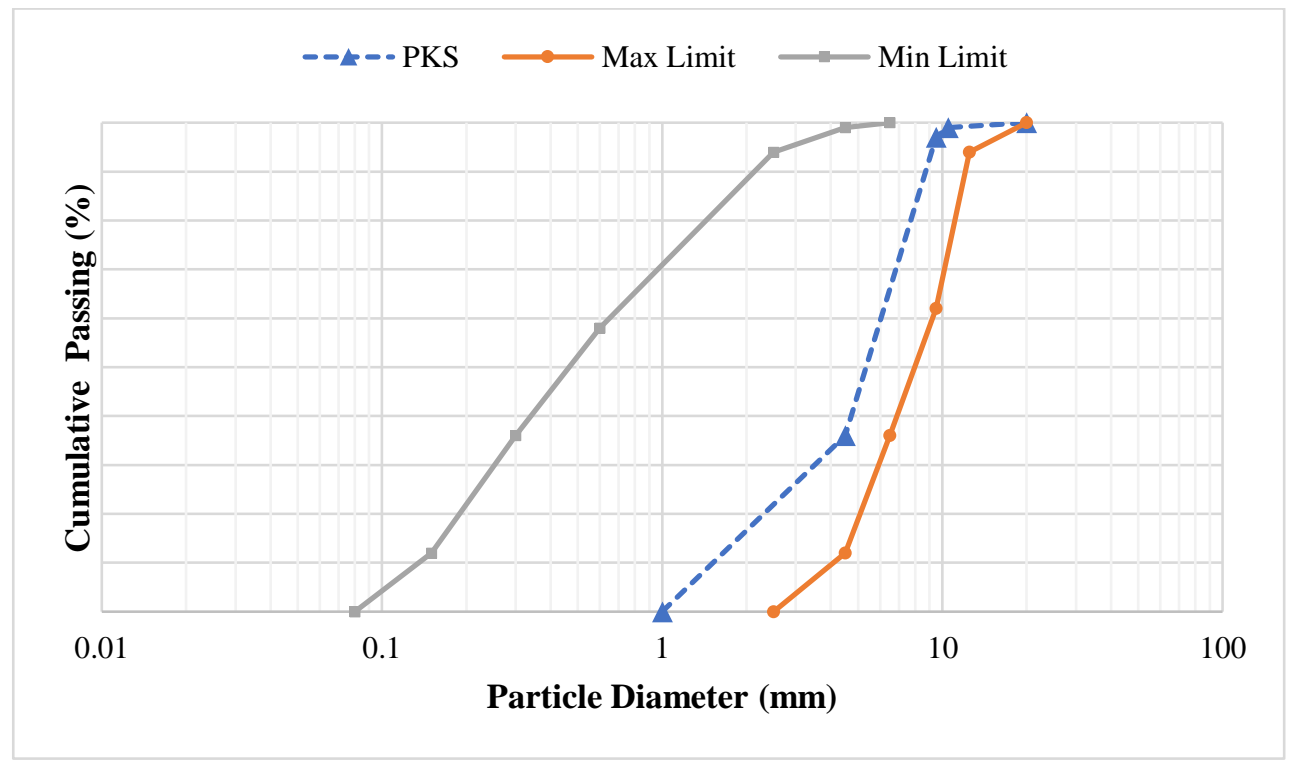

Figure 1. Particle distribution curve for PKS aggregate 

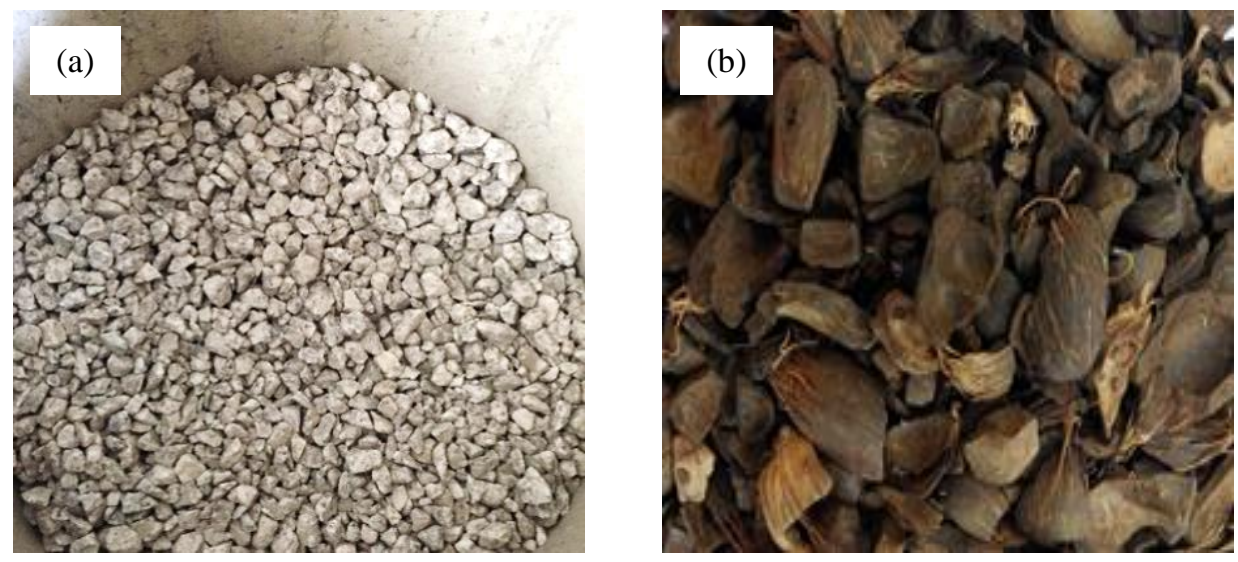

Figure 2. Appearance of natural aggregate (a) and PKS aggregate (b)

\section{Mix Design and Testing Procedures}

This present study was conducted to investigate the effect of PKS as an aggregate replacement to pervious concrete mixture. For (4) series of pervious concrete that contain different levels of percentage of PKS were prepared. The control concrete mix (control PC) was prepared using conventional aggregate, while the pervious concrete incorporating PKS aggregate were prepared by replacing the PKS amount with different percentage levels. The aggregates were replaced with PKS at $0,10,15$ and $20 \%$ of the total weight of aggregate used. All the pervious concrete mixes were labelled as control PC, PKS10, PKS15 and PKS20, respectively. Table 1 displays the mix designation for the control PC and a series of PKS-pervious concrete used in this study. The water to cement ratio used was constant at 0.37 for all mixes. After mixing the concrete, the fresh concrete was poured and casted in a $100 \mathrm{~mm}$ cube steel moulds, and $100 \mathrm{~mm} \times 100 \mathrm{~mm} \times$ $500 \mathrm{~mm}$ prism steel moulds. The entire cast specimens were compacted by using a mechanical vibrated machine. The pervious concrete specimens were demoulded approximately 24 hours after casting and were cured in water at $25 \pm 2{ }^{\circ} \mathrm{C}$ until the age of testing. In this study, the testing method can be divided to three (3) tests comprises of density (fresh and hardened), void content and compressive strength were performed. The density and void content test conducted was followed ASTM C1754M-12. The void content is a test to determine the total percentage of voids present by volume in cube specimens. The fresh density for all pervious concrete mixes were measured immediately after mixing process. Meanwhile, the hardened density and void content were determined after the specimens were dried in an oven at $100 \pm$ $2{ }^{\circ} \mathrm{C}$ for 24 hours. This procedure was performed one (1) day before the compressive strength tests. For the compressive strength test, the recommendations of BS EN 12390-3 were followed, and the flexural strength test was conducted according to BS EN 12390-5. All the testing for hardened specimens were determined at 7 and 28 days.

Table 1. Mix proportion for control PC and a series of PKS-pervious concrete

\begin{tabular}{lllll}
\hline \multirow{2}{*}{ Mix Designation } & \multicolumn{3}{l}{ Raw Materials $\left(\mathrm{kg} / \mathrm{m}^{3}\right)$} & \multicolumn{3}{c}{ Aggregate } & \multirow{2}{*}{ Water } \\
\cline { 2 - 5 } & \multirow{2}{*}{ Cement } & Natural & PKS & \\
\hline Control PC & 301 & 1574.00 & 0 & 111 \\
PKS10 & 301 & 1416.60 & 157.40 & 111 \\
PKS15 & 301 & 1337.90 & 236.10 & 111 \\
PKS20 & 301 & 1259.20 & 314.80 & 111 \\
\hline
\end{tabular}

\section{RESULTS AND DISCUSSION}

\section{Fresh and Hardened Density}

The fresh and hardened density for all mixtures of concrete is depicted in Figure 3. The densities for fresh PKS10, PKS15 and PKS20 mixes were found to be 1605,1490 and $1385 \mathrm{~kg} / \mathrm{m}^{3}$ lower than the control mix without PKS (1800 $\mathrm{kg} / \mathrm{m}^{3}$ ). An increase in PKS aggregate leads to a gradual decrease in density. The fresh density for PKS-pervious concrete was reduced in volume from 11 to $23 \%$ as compared to the control PC, respectively. It is clear that increased level PKS aggregate has significantly reduced the fresh density for all PKS-pervious concrete mixes. Further, the densities of hardened control PC and pervious concrete produced using various PKS aggregate recorded are 1705, 1498, 1428 and $1350 \mathrm{~kg} / \mathrm{m}^{3}$, respectively. It is identified that the effect of PKS aggregate in hardened pervious concrete is slighter than the fresh density. The integration of PKS as partial aggregate replacement decreases the concrete densities. The density for pervious concrete containing 10,15 and 20\% PKS was reduced from 12, 16 and $21 \%$ of volume compared to the control PC, respectively. This can be attributed to the shape of PKS aggregate varies from angular to polygonal causing a separation between the PKS particles and cement paste. This was confirmed by Ibrahim \& Abdul Razak [10] and Khankhaje et al. [13] who found that the density of pervious concrete is relatively dependent on the aggregate used, the porous nature of PKS having lower specific gravity and density can be said to have directly influenced the density of 
PKS-pervious concrete. No doubt, the PKS aggregate used in this study has low specific gravity and density compared to natural aggregate. This is in line with the findings of previous studies on PC mixtures [21, 22]. In this present finding, all the hardened PKS-PC densities are responsible lower than the typical limit $\left(1600 \mathrm{~kg} / \mathrm{m}^{3}\right)$ [18].

Figure 4 shows the relationship between fresh and hardened density for control PC and pervious concrete incorporating PKS aggregate. It can be observed that the fresh density was slightly higher than the hardened density as expected. This fact is attributed to the water loss during the hydration process. Moreover, PKS aggregate extremely higher water absorption. A similar trend has been observed when oil palm shell (OPS) aggregates were used in high strength lightweight concrete [24]. The empirical linear relationship between fresh density and hardened (dry) density is expressed by the following equation and presented in Equation 1. It is observed that there is a good linear relationship between fresh and dry densities for mixes and high correlation coefficient, $\mathrm{R}^{2}$ is 0.9848 , which close to 1.0.

$$
\mathrm{D}_{\mathrm{h}}=0.8507 \mathrm{D}_{\mathrm{f}}+159.77
$$

where $D_{h}$ is dry (hardened) density, $\mathrm{kg} / \mathrm{m}^{3}$ and $D_{\mathrm{f}}$ is fresh density, $\mathrm{kg} / \mathrm{m}^{3}$.

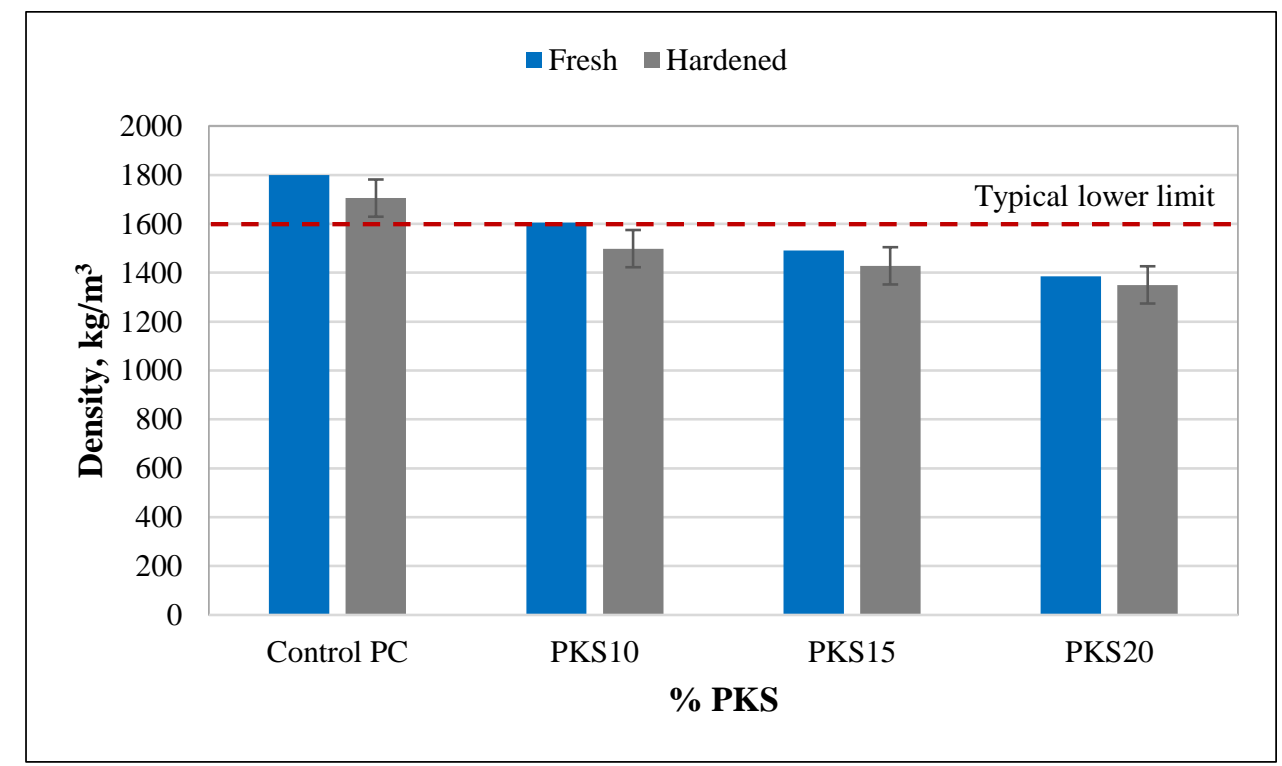

Figure 3. Fresh and hardened density of PKS-pervious concrete

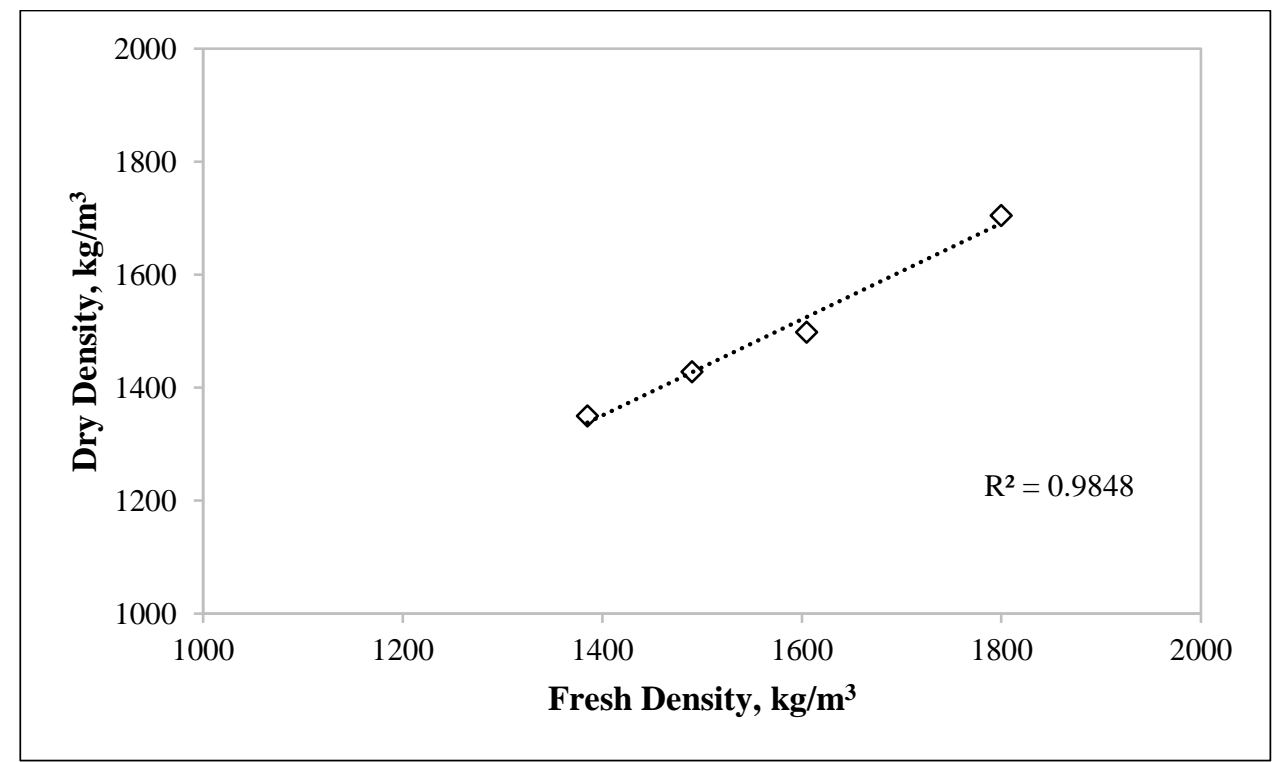

Figure 4. Relationship between dry density and fresh density

\section{Void Content}

Figure 5 charted the porosity for three series of modified pervious concrete contained PKS aggregate recorded at 7 and 28 days with reference to control PC. On day 7, it is observed that the void content for PKS-pervious concrete increased with the increase of level percentage PKS when compared to control PC. Similar trends were also recorded when the increment amount of PKS aggregate, the porosity in pervious concrete slightly decreased with the prolonged age. The void content of PKS10, PKS15 and PKS20 is about 1.02, 1.03 and 1.08 times highest than control PC at 28 days, 
respectively. As expected, PKS20 showed in larger void spaces among the PKS-pervious concrete. It can be noted that the void content of PKS20 was about 36.67 and $33.71 \%$ of volume corresponding to curing age. The results also found that PKS20 with a high percentage of interconnected void, allowing water to drain through its interconnected void in the concrete. In addition, the porosity of all the PKS-pervious concrete (at 28 days) ranging between approximately 0.16 to $8 \%$ higher than the typical limit but is still acceptable to the limit according to ACI522 [18]. This was confirmed by Ibrahim \& Abdul Razak [10] and Khankhaje et al. [13, 14] who found that the density of is relatively dependent on the aggregate used, the porous nature of PKS aggregate having lower specific gravity and density can be said to have directly influenced the density of PKS-pervious concrete. No doubt, the PKS particle used in this study owning low specific gravity (1.26) and density $\left(1259 \mathrm{~kg} / \mathrm{m}^{3}\right)$. It can be said that pervious concrete contained PKS aggregate provides porosity level that allows water to penetrate into the concrete. Therefore, the percentage of void content achieved in this study is comparable to the studied by Nguyen et al. [22] and Zaetang et al. [25].

Obviously, when the density of hardened concrete decreased, the void content in the PKS-pervious concrete samples increased. The relationship between void content and dry (hardened) density for all mixes at 28 days are demonstrated in Figure 6. It can be remarked that the porosity of concrete noticeably affects the density of concrete. As the replacement levels percentage of PKS aggregate in pervious concrete increased, the unfavorable effects became more pronounced which caused the effective void formation to increase and resulted lower densities. However, the linear has a $\mathrm{R}^{2}$ value of 0.6246 which is not satisfactory. The linear equation between void content and dry density is expressed in Equation 2 .

$$
\mathrm{D}_{\mathrm{h}}=-103.11 \mathrm{~V}_{\mathrm{C}}+4801.1
$$

where $\mathrm{D}_{\mathrm{h}}$ is dry density $\left(\mathrm{kg} / \mathrm{m}^{3}\right)$ and $\mathrm{V}_{\mathrm{C}}$ is void content $(\%)$.

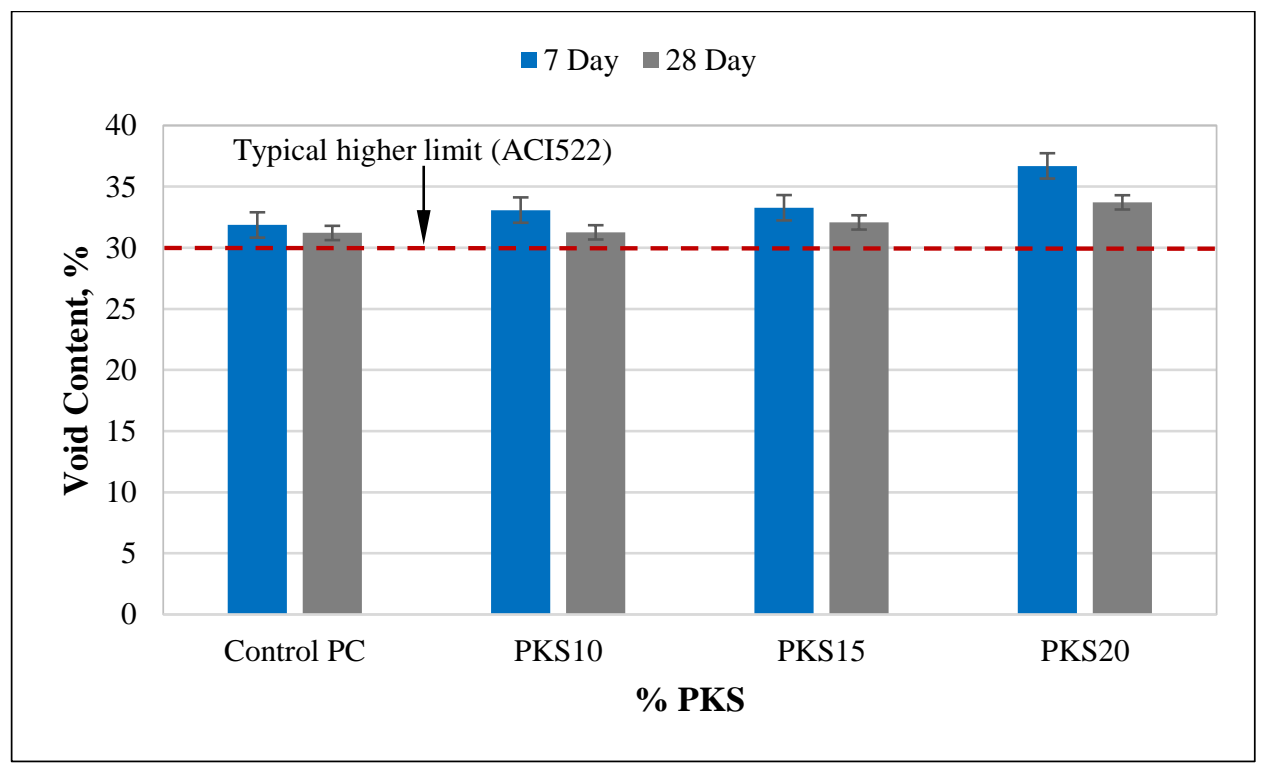

Figure 5. Influence of PKS aggregate content on void content of pervious concrete

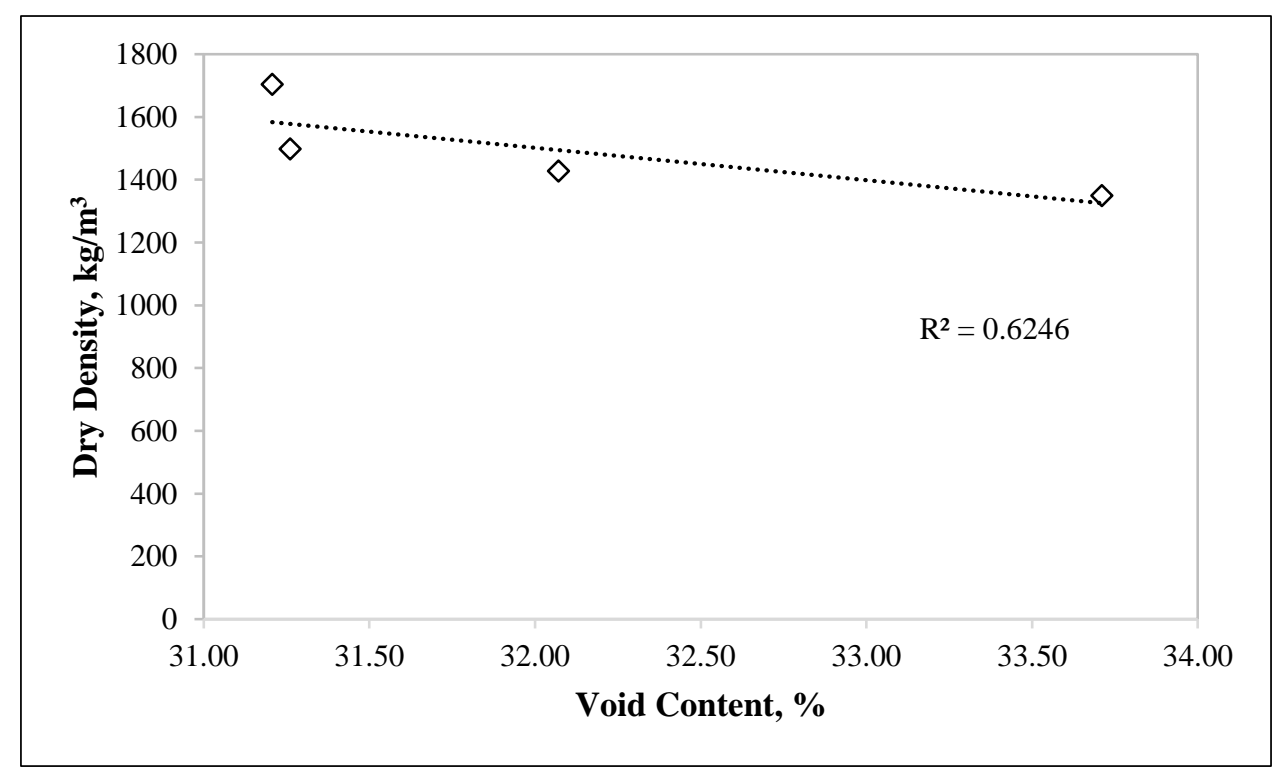

Figure 6. Relationship between dry density and void content 


\section{Compressive Strength}

The compressive strength of all the pervious concrete mixtures at 7 and 28 day age after curing are presented in Figure 7. It is observed that the inclusion of PKS aggregate reduces the compressive strength and a lower than those of the control PC. On day 7, the control PC sample had the highest compressive strength $(5.75 \mathrm{MPa})$, followed by a series of PKSpervious concrete samples. The lack of cement paste to bind the aggregate and PKS aggregate together is implicated the strength development. Prolong curing age has a significant effect on the compressive strength due to continued hydration process. The beneficial effect of prolonged curing towards positive concrete strength gain has been highlighted by Zaetang et al. [25]. However, increasing the PKS content from 0 to $20 \%$, decreased the compressive strength from 10.24, 9.76, 6.50, and 5.81 MPa, correspondingly, after 28 days. The compressive strength value of the PC mixture containing $10 \%$ of PKS was almost comparable to the value of the control PC. Pervious concrete mixture up to $20 \%$ showed a reduction in compressive strength values. It is believed that as the amount of PKS increases, the bond between cement pastes and PKS particles weakens. Because of inter-aggregate bonding is crucial for pervious concrete strength, the thickness of cement paste on the aggregate and PKS aggregate has a significant impact on pervious concrete strength. Furthermore, as the age increased, the compressive strength of all the PKS-pervious concrete increased as well. PKS10 demonstrated the highest compressive strength at all ages. Prolong curing age has a significant effect on the compressive strength due to the continued hydration process. Among all the three (3) mixes of pervious concrete based PKS, it is revealed that PKS10 gives better results than those of PKS-pervious concrete. Previous studies indicate that the compressive strength of pervious concrete incorporating agro-forestry waste materials as an aggregate replacement can be developed strength is remarkable in ranges of 6 to $14 \mathrm{MPa}$ depending on mix proportion, aggregate size, and water-to-cement $[8,11,13,14]$. It is important to mention that although the use of PKS aggregate up to $20 \%$ adversely affected the compressive strength of pervious concrete but the achieved results still fulfil the proposed typical ranges by ACI 522R [18].

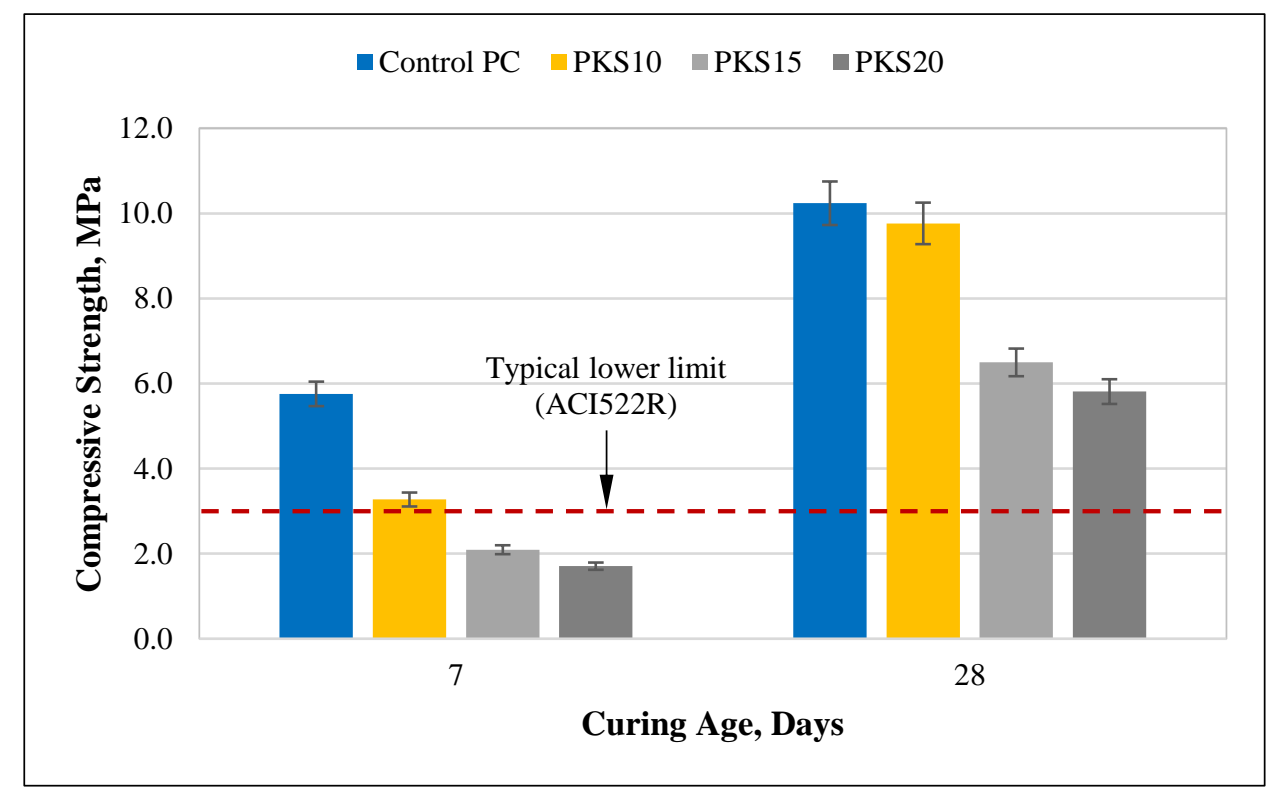

Figure 7. Influence of PKS aggregate on compressive strength

In addition, several factors should be considered, such as the strength of cement paste, the thickness of cement paste coating the aggregates and the interface between aggregate and cement paste. Azunna [26] and Ahmed \& Hoque [3] used cement content of 548 and $315 \mathrm{~kg} / \mathrm{m}^{3}$, the compressive strength recorded was below $10 \mathrm{MPa}$. A similar trend has also been observed by Ibrahim and Abdul Razak [10] and Pratap et al. [27] employed more cement and discovered that the compressive strength of pervious concrete was around $10 \mathrm{MPa}$. Since pervious concrete contains no fine aggregate, strength depends primarily on the interaction between cement paste and coarse aggregate thus high porosity in pervious concrete reduces compressive strength. Therefore, the compressive strength of PKS10 (9.76 MPa) obtained was in the ranged and comparable to the results obtained from those previous researchers.

\section{Flexural Strength}

The influence of PKS aggregate replacement levels in pervious concrete mixture is shown in Figure 8. It is clear that the use of PKS aggregate has a significant effect on flexural strength where the increase of PKS aggregate content decreases the resulting concrete flexural strength. The results showed that the flexural strength for PKS10, PKS15 and PKS20 decreased about 47, 63 and 71\%, respectively, corresponding to control PC for 7 days. At 28 days, the flexural strength of the control PC and a series of PKS-pervious concrete was found to be 3.60, 2.14, 1.34 and $1.10 \mathrm{MPa}$, respectively. Prolong curing age significantly affect on the flexural strength due to continued hydration process [24]. The highest strength obtained at 28 days was those designated as control PC recorded 3.60 MPa of flexural strength. From the result, the increase of PKS aggregate content decreases 28 days pervious concrete flexural strength. The reduction in 28 days pervious concrete flexural strength is 40,63 and $69 \%$ with reference to the control PC. The negative effect of using 
PKS aggregate may be attributed to the characteristics of PKS aggregate. It was caused by the angular form and interconnected composition of the PKS aggregate led to a reduction of compaction and increased the void space. Obviously, it indicates that the use of PKS aggregate up to $20 \%$, generally yields flexural strength more than recommend ranges by ACI 522R [18]. Inclusion of $10 \%$ PKS aggregate recorded the highest flexural strength among all the PKSpervious concrete specimens. The flexural strength of PKS10 was developed gradually begin from day 7 and significantly increased until 28 days. According to El-Hassan et al. [20], the flexural strength in pervious concrete ranging between 1 to 3.8 MPa. Several factors influence the flexural strength, particularly the degree of compaction, void content, and the aggregate-to-cement ratio [12]. Thus, the use of $10 \%$ PKS is recommended to be used as an aggregate replacement to produce pervious concrete. Moreover, the flexural strength of PKS10 achieved was in the ranged and comparable to the results obtained from those previous researchers.

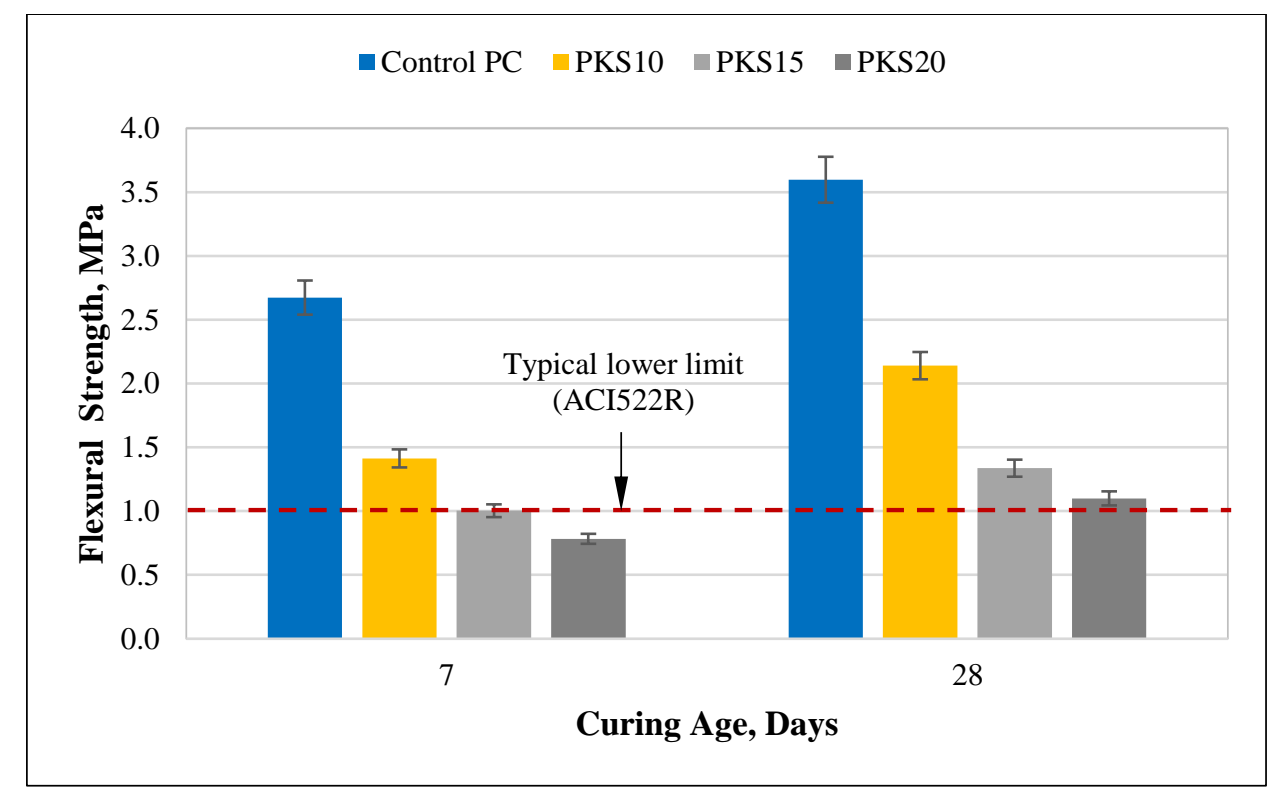

Figure 8. Influence of PKS aggregate on flexural strength

\section{Relationship between Density and Mechanical Properties of PKS-Pervious Concrete}

Figure 9 charted the relationship between dry density towards compressive strength and flexural strength at 28 days for all mixes. The models for dry density versus compressive strength and flexural strength is also represented by a linear relationship. It can be seen that the lower in densities and, consequently, may not result in an increase in strength properties for all PKS-pervious concrete samples. This fact can be attributed to the larger void space formation in the PKS-pervious concrete resulted in density reduction. A linear correlation between compressive strength and density can be deduced from the graph plotted in the figure. The strong correlation between compressive strength and density can be observed. The $\mathrm{R}^{2}$ value was 0.9039 for Equation 3, signifying strong certainty for the relation. This means that $90.39 \%$ of the variation in compressive strength is more dominant on the density of the concrete.

$$
\mathrm{S}_{\mathrm{C}}=-1.6547 \mathrm{D}_{\mathrm{h}}+12.213
$$

where $\mathrm{S}_{\mathrm{C}}$ is compressive strength $(\mathrm{MPa})$ and $\mathrm{D}_{\mathrm{h}}$ is dry density $\left(\mathrm{kg} / \mathrm{m}^{3}\right)$.

Based on Figure 9, it can be also seen the relationship between flexural strength and densities for all mixes. A linear correlation was also applied to correlate the experimental results. A regression analysis indicates that $90.23 \%\left(\mathrm{R}^{2}\right.$ is 0.923$)$ of the variability in flexural strength can be attributed to its density. Therefore, it is shown that the relationship was strong. The empirical relationship between flexural strength and density is expressed in Equation 4.

$$
\mathrm{S}_{\mathrm{F}}=-0.8293 \mathrm{D}_{\mathrm{h}}+4.1167
$$

where $S_{F}$ is flexural strength $(\mathrm{MPa})$ and $\mathrm{D}_{\mathrm{h}}$ is dry density $\left(\mathrm{kg} / \mathrm{m}^{3}\right)$. 


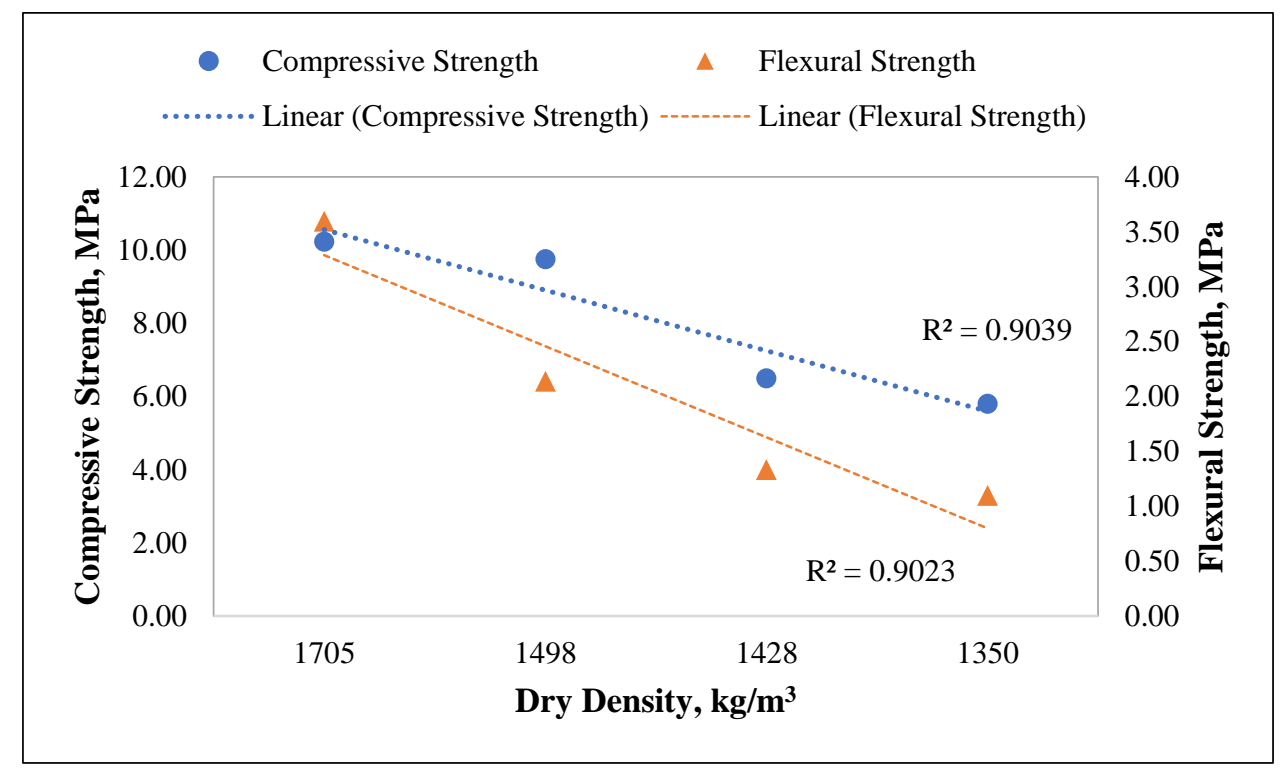

Figure 9. Relationship between dry density against mechanical properties

Finally, it is revealed that the lower density in concrete significantly affect the concrete strength. As the amount of PKS aggregate increased up to $20 \%$, the strength reduction was recorded for previous concrete. However, the strength recorded for all PKS mix proportions fall within the range for pervious concrete [18]. It is also demonstrated that $10 \%$ of PKS aggregate was an optimum content to replace the natural aggregate. This amount was found just good fill up size pores in concrete.

\section{CONCLUSIONS}

It can be concluded that PKS aggregate is significantly had the potential to be used in pervious concrete with the desired strength. The inclusion of PKS as a partial substitute for aggregate negatively affected the strength due to reduction in density of pervious concrete, however the achieved results still fulfilling the proposed typical range for compressive strength and flexural strength of pervious concrete. By incorporating PKS aggregate up to $20 \%$, environmentally friendly pervious concrete based PKS aggregate can be produced in lieu of conventional pervious concrete. Among, the PKS-pervious concrete, it was discovered that the use of $10 \%$ PKS aggregate in pervious concrete is sufficient and marked superior in physical and mechanical properties.

\section{REFERENCES}

[1] Guntakal, S. N. and Selvan, S. “Application of Pervious Concrete for Pavements: A Review”, Rasayan J. Chem., 10(1), 32-26, 2017, doi.10.7324/RJC.2017.1011533.

[2] Deo, O. and Neithalath, N. "Compressive Behavior of Previous Concretes and a quantification of the influence of random pore structure features”, Mat. Sci. Eng.: A, 528(1), 402-412, 2010, doi.10.1016/j.msea.2010.09.024.

[3] Ahmad, T. and Hoque, S. "Study on Previous Concrete Pavement Mix Design", IOP Conf. Ser.: Earth Environ. Sci., 476, 012062, 2020, doi.10.1088/1755-1315/476/1/012062.

[4] Mehta, S., Shah, Y., Surti, V. and Shah, R. "Study on Compressive Strength and Permeability of PC", Int. J. Eng. Res. Technol, 5(4), 669-671, 2016, doi.org/10.1016/j.matpr.2020.10.839.

[5] Elango, K. S., Gopi, R., Saravanakumar, R., Rajeshkumar, V., Vivek, D. and Venkat Raman, S. "Properties of Previous Concrete- A State of the Art Review", Mater. Today: Proc., 45, 2422-2425,

[6] Ong, S. K., Wang, K., Ling, Y. and Shi, G. "Pervious Concrete Physical Characteristics and Effectiveness in Stormwater Pollution Reduction”, InTrans Project Report, 197, 2016.

[7] Elizondo-Martinez, E. J., Andrés-Valeri, V. C., Jato-Espino, D., and Rodriguez-Hernandez, J. "Review of Porous Concrete as Multifunctional and Sustainable Pavement", J. Build. Eng., 27: 100967, 2020, doi.10.1016/j.jobe.2019.100967.

[8] Debnath, B. and Sarkar, P. P. "Characterization of PC using Over Burnt Brick as Coarse Aggregate", Constr. Build. Mater., 242, 118154, 2020, doi.10.1016/j.conbuildmat.2020.118154.

[9] AlShareedah, O. and Nassiri, S. "Pervious Concrete Mixture Optimization, Physical, and Mechanical Properties and Pavement Design: A review”, J. Clean. Prod., 288, 125095, 2021. doi.org/10.1016/j.jclepro.2020.125095.

[10] Ibrahim, H. A. and Razak, H. A. "Effect of Palm Oil Clinker Incorporation on Properties of Pervious Concrete", Con. Build. Mat., 115, 70-77, 2016, doi.10.1016/j.conbuildmat.2016.03.181.

[11] Liu, R., Xiao, H., Pang, S. D, Geng, J., and Yang, H. “Application of Sterculia Foetida Petiole Wastes in Lightweight Pervious Concrete", J. Clean. Prod., 246, 118972, 2020, doi.10.1016/j.jclepro.2019.118972.

[12] Oyejobi, D. O., Jameel, M., Sulong, N. H. R, Raji, S. A., and Ibrahim, H. A. "Prediction of Optimum Compressive Strength of Light-weight Concrete Containing Nigerian Palm Kernel Shells”, J. king Saud Univ. Eng. Sci., 32, 303-309, 2020. doi.org/10.1016/j.jksues.2019.04.001.

[13] Khankhaje, E., Salim, M. R., Mirza, J., Hussin, M. W. and Rafieizonooz, M. "Properties of Sustainable Lightweight Pervious Concrete Containing Oil Palm Kernel Shell as Coarse Aggregate", Con. Build. Mat., 126, 1054-1065, 2016, 
.doi.10.1016/j.conbuildmat.2016.09.010.

[14] Khankhaje, E., Rafieizonooz, M., Salim, M. R., Mirza, J., Salmiati and Hussin, M. W. "Comparing the Effects of Oil Palm Kernel Shell and Cockle Shell on Properties of Pervious Concrete Pavement", Int. J. Pavement Res.Technol., 10(5): 383-392, 2017, doi.org/10.1016/j.ijprt.2017.05.003.

[15] Khankhaje, E., Salim, M. R., Mirza, J., Salmiati, Hussin, M. W., Khan, R. and Rafieizonooz, M. "Properties of Quiet Pervious Concrete Containing Oil Palm Kernel Shell and Cockleshell”, Appl. Acoust., 122, 113-120, 2017, doi.org/10.1016/j.apacoust.2017.02.014.

[16] Kia, A, Wong, H. S., Cheeseman, C. R. "Clogging in Permeable Concrete: A Review", J. Environ. Manage., 193, 221-223, 2017, doi.10.1016/j.jenvman.2017.02.018.

[17] Sharif, A. A. M., Shahidan, S., Koh, H. B., Kandash, A., Mohd Zuki, S. S. "Strength Development of Pervious Concrete Containing Engineering Biosmass Aggregate", IOP Conf. Ser.: Mater. Sci. Eng., 271, 012002, 2017, doi.10.1088/1757899X/271/1/012002.

[18] ACI 522. "Report on Pervious Concrete", American Concrete Institute. 2010.

[19] Sah, S. K., Guntakal, S. N. and Selvan, S. S. "Experimental Study on Behavior of Pervious Concrete in Strength and Permeability by Changing Different Parameters", Int. J. Appl. Eng. Res., 6, 4550-4554, 2018.

[20] El-Hassan, H., Kianmehr, P., and Zouaoui, S. "Properties of Pervious Concrete Incorporating Recycled Concrete Aggregates and Slag", Con. Build. Mat., 212, 164-175, 2019, doi.org/10.1016/j.conbuildmat.2019.03.325.

[21] Hamada, H. M., Jokhio, G. A., Al-Attar, A. A., Yahaya, F. M., Muthusamy, K., Humada, A. M. and Gul, Yasmeen. "The Use of Palm Oil Clinker as a Sustainable Construction Material: A Review”, Cem. Concr. Compos., 106, 103447, 2020, doi.10.1016/j.cemconcomp.2019.103447.

[22] Nguyen, D. H., Boutouil, M., Sebaibi, N., Baraud, F. Leleyter, L. "Durability of Pervious Concrete using Crushed Seashells", Cons. Build. Mat., 135, 137-150, 2017, doi.10.1016/j.conbuildmat.2016.12.219.

[23] Lu, J. X., Yan, X., He, P. and Poon, C. S. "Sustainable Design of Pervious Concrete using Waste Glass and Recycled Concrete Aggregate", J. Cleaner Production, 234, 1102-1112, 2019.

[24] Yew, M. K., Mahmud, H., Ang, B. C. and Yew, M. C. "Effect of Heat Treatment on Oil Palm Shell Coarse Aggregate for High Strength Lightweight Concrete”, Mater. Des., 54, 702-707, 2014, doi.org/10.1016/j.matdes.2013.08.096.

[25] Zaetang, Y., Wongsa, A., Sata, V. and Chindaprasirt, P. "Use of Lightweight Aggregates in Pervious Concrete", Constr. Build. Mater., 48, 585-591, 2013, doi.org/10.1016/j.conbuildmat.2013.07.077.

[26] Azunna, S. U. "Compressive Strength of Concrete with Palm Kernel Shell as a Partial Replacement for Coarse Aggregate", $S N$ Applied Sciences, 1(4), 342, 2019.

[27] Pratap, S. H., Rakesh, S., Kapil, S. and Kumar, K. S. "Enhancement the Strength of Pervious Concrete with Different Water Cement Ratio and Admixture', Int. J. Eng. Res.. 5(1), 582-588, 2016. 